\title{
RESISTÊNCIA ÀS POLIMIXINAS EM BACTÉRIAS GRAM-NEGATIVAS: UMA REVISÃO MICROBIOLÓGICA
}

\section{POLYMYXINS RESISTANCE IN GRAM-NEGATIVE BACTERIA: A MICROBIOLOGICAL REVIEW}

\begin{abstract}
Carvalho, Vinícius Dal’Negro'; Cogo, Laura Lúcia²
1-Graduando do Curso de Farmácia das Faculdades Integradas do Brasil. E-mail: vinnes2anne@gmail.com

2-Professora Doutora do Curso de Farmácia das Faculdades Integradas do Brasil. Farmacêutica do Laboratório de Bacteriologia do Hospital de Clínicas da Universidade Federal do Paraná.
\end{abstract}

\section{RESUMO:}

Antibióticos são substâncias químicas antimicrobianas que tem a finalidade de inibir o crescimento de microrganismos ou destruí-los. As polimixinas são antimicrobianos empregados no tratamento de infecções causadas por bacilos Gram-negativos, atuando na desestabilização da membrana externa bacteriana e causando a sua morte. O uso desse fármaco reemergiu nos últimos anos devido ao número crescente de microrganismos multirresistentes às classes de antimicrobianos comumente empregados, sendo a última escolha no tratamento de cepas resistentes. Entretanto, estudos realizados em todo mundo já relataram resistência às polimixinas, principalmente na América Latina e Ásia, evidenciando um problema de saúde pública mundial.

Palavras-chave: Polimixinas, Resistência Bacteriana, Bactérias Gram-negativas.

\section{ABSTRACT:}

Antibiotics are antimicrobial chemical substances that have the purpose of inhibiting the growth of microrganisms or destroy them. The polymyxins are antimicrobial agents used in the treatment of infections caused by Gram-negative bacilli, acting in the destabilization of the bacterial outer membrane and causing its death. The use of this drug has reemerged in recent years due to the increasing number of multiresistant microrganisms to classes of antimicrobials commonly used, being the last choice in the treatment of resistant strains. However, worldwide researches have already reported resistance to the polymyxins, mainly in Latin America and Asia, indicating a global public health problem.

Key Words: Polymyxins, Bacterial Resistance, Gram-negative Bacteria. 


\section{INTRODUÇÃO}

Antibióticos são substâncias químicas antimicrobianas que têm por finalidade inibir o crescimento de microrganismos ou causar a sua destruição. As polimixinas são antimicrobianos polipeptídicos que atuam inativando a porção lipídica $\mathrm{A}$ da endotoxina presente na membrana externa da bactéria ocasionando a morte bacteriana (MENDES; BURDMANN, 2009). Essa classe de medicamentos possue cinco tipos de fármacos, porém, apenas a Polimixina $B$ e a Polimixina $E$ (colistina) são utilizadas clinicamente (FALAGAS et al., 2010). De acordo com Oliveira e colaboradores (2009), esses dois fármacos são comparáveis tanto na eficácia clínica, quanto na toxicidade renal.

A despeito do espectro de ação, o alvo desse fármaco são as bactérias Gramnegativas. Os relatos de resistência tornaram-se um problema de saúde pública de ordem mundial, sendo cada vez mais relevantes os estudos que elucidem os mecanismos dessa resistência e que incentivem o desenvolvimento de novos medicamentos. Isso se deve ao fato de que as polimixinas são a última opção de escolha para o tratamento de bacilos Gram-negativos multirresistentes às demais classes de antimicrobianos utilizados em hospitais para o tratamento de infecções oportunistas (GALES et al., 2011).

O objetivo desse trabalho é revisar os mecanismos de resistência às polimixinas desenvolvidos por bactérias Gram-negativas e verificar a sua prevalência, descrevendo suscintamente as metodologias padronizadas para caracterização da resistência in vitro frente a esse fármaco.

\section{POLIMIXINAS}

\subsection{Histórico}

As Polimixinas foram descobertas no final dos anos 40 , descritas de forma independente por pesquisadores norte-americanos e ingleses. Elas constituem um grupo de cinco compostos químicos intimamente relacionados, as Polimixinas $A, B, C$, D e E (MENDES; BURDMANN, 2009). Dentro desse grupo, duas substâncias apresentam aplicação terapêutica. A primeira é a polimixina $B$, que foi descoberta em 1947, isolada a partir de Bacillus polymyxa. A segunda compreende a polimixina $\mathrm{E}$ ou Colistina, descoberta em 1950, isolada a partir da espécie Bacillus colistinus. As demais não são utilizadas clinicamente devido à sua alta taxa de toxicidade (MOSTARDEIRO, 2009).

O uso das polimixinas reemergiu nos últimos anos como terapia de resgate no tratamento de bacilos Gram-negativos multirresistentes, baseado em experiências 
empíricas e séries de casos. Mais recentemente, estudos farmacocinéticos e farmacodinâmicos têm sido realizados para melhor avaliação da ação destas drogas (ZAVASCKI et al., 2010).

\subsection{Estrutura Química}

As polimixinas B e E são detergentes policatiônicos, cuja estrutura química básica é composta por um decapeptídeo cíclico e uma cadeia tripeptídea com um ácido graxo na extremidade, possuindo elevada porcentagem de resíduos de ácido 2,4diaminobutírico (Dab) e uma cadeia de ácido graxo aderida ao anel heptapeptídeo, através de uma ligação amida (KVITKO, 2010). A colistina diferencia-se da polimixina B pela presença do aminoácido D-leucina no lugar de D-fenilalanina na posição seis (MENDES; BURDMANN, 2009).

Polimixina B é uma mistura de sulfatos de polipeptídeos contendo quatro componentes relacionados, polimixina B1 a B4, sendo a maioria dos componentes a polimixina B1 e polimixina B2 que contém os ácidos graxos 6-metiloctanoico e 6metilheptanoico, respectivamente. Os quatros componentes diferem entre si apenas pelo ácido graxo (ELIAS, 2010). Trata-se de um antibiótico anfipático, conferindo, assim, uma propriedade de distribuição boa em ambientes aquosos ou não aquosos, o que resulta em boa solubilidade em água ou sangue, e em membranas lipídicas procarióticas e eucarióticas (MOSTARDEIRO, 2009).

Em termos de potência in vitro, sulfato de polimixina $B$ é o mais potente composto, comparado com sulfato de colistina e colistimetato de sódio. O colestimetato de sódio (CMS) é um pró-fármaco da colistina, menos potente em comparação com o composto original e parece causar menos efeitos adversos (MENDES; BURDMANN, 2009). Ambas as moléculas possuem estruturas distintas, sendo a colistina um policátion e o CMS um poliânion em pH fisiológico. Em comparação com o CMS, a colistina é duas a quatro vezes mais ativa contra $P$. aeruginosa (ELIAS, 2010).

\subsection{Espectro e Mecanismo de Ação}

As polimixinas em concentração $<2 \mu \mathrm{g} / \mathrm{mL}$, possuem excelente atividade sobre diversos bacilos Gram-negativos fermentadores e não fermentadores de glicose, principalmente contra espécies de Klebsiella spp., Escherichia coli, Enterobacter spp., Salmonella spp., Shigella spp., P. aeruginosa e Acinetobacter spp., incluindo isolados resistentes a outras classes de antibióticos (ELIAS, 2010).

O mecanismo de ação das polimixinas ainda não está completamente esclarecido. Esses fármacos atuam primariamente nas membranas externa e citoplasmática, com ação semelhante à de detergentes catiônicos simples. 
As polimixinas ligam-se aos componentes do envelope celular como fosfolipídios e

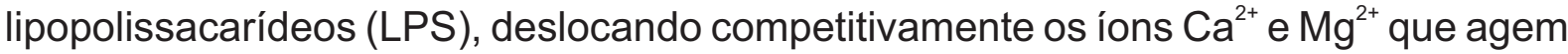
como estabilizadores da membrana, provocando ruptura da mesma, levando à perda do conteúdo celular e ocasionando morte da bactéria. Essa ação parece ser inibida na presença desses cátions divalentes (CHAMBERS, 2005).

\subsection{Farmacocinética}

A recomendação atual intravenosa da polimixina $B$ ao paciente com função renal normal é de 1,5 - 2,5 mg. $\mathrm{kg}^{-1}$.dia ${ }^{-1}$ dividida em 2 doses, administradas em 1 hora de infusão contínua. Para pacientes com disfunção renal, a sugestão é administrar doses ajustadas que incluem decréscimo de dose diária e administração de intervalos prolongados (ELIAS, 2010).

Entretanto, alguns estudos mostraram que, após a administração das doses atualmente recomendadas, o nível sérico máximo atingido variava de 2 a $14 \mu \mathrm{g} \cdot \mathrm{ml}^{-1} \mathrm{e}$ que a ligação protéica da droga é de cerca de $90 \%$. Desse modo, a concentração de droga livre fica próxima ou inferior à concentração inibitória mínima (CIM) de susceptibilidade (<2 $\mu \mathrm{g} \cdot \mathrm{ml}^{-1}$ ) (RIGATTO, 2011). Outro estudo relatou que menos de $1 \%$ de polimixina B infundida foi recuperada inalterada na urina (KWA et al., 2008). As polimixinas são pouco retiradas no processo de diálise (KVITKO, 2010).

Em relação ao CMS, a depuração ocorre por via renal (aproximadamente 60\% nas primeiras 24 horas), enquanto que a colistina é eliminada por vias diferentes não totalmente conhecidas (ELIAS, 2010). A distribuição da droga é escassa para líquor, trato biliar, líquido pleural e líquido sinovial (KVITKO, 2010).

\subsection{Farmacodinâmica}

As polimixinas in vitro são rapidamente bactericidas no modelo concentração dependente. Uma das evidencias que comprova esse fato está no efeito pós-antibiótico para $P$. aeruginosa, mas não para $A$. baumannii. Um estudo através da metodologia time-kill examinou a farmacodinâmica na polimixina $B$, demonstrando que um crescimento foi observado após rápida redução inicial da lise bacteriana em todas as concentrações testadas (1-16 mg/L). Um modelo in vitro sugeriu que a administração de polimixina três vezes ao dia poderia ser efetiva em suprimir a resistência (KVITKO, 2010).

Um estudo in vivo em camundongos neutropênicos, com colistina em infecções musculares e pulmonares por $P$. aeruginosa, demonstrou claramente que o perfil farmacocinético/farmacodinâmico ótimo dessa droga é o tempo da área abaixo da curva tempo/concentração inibitória mínima. Assim, ressalta-se a importância de atingir 
um equilíbrio de exposição a altas concentrações da droga e tempo de exposição à mesma (ELIAS, 2010).

\subsection{Efeitos Adversos}

Os efeitos adversos mais importantes das polimixinas são nefrotoxicidade (principalmente insuficiência renal aguda) e neurotoxicidade. Outros efeitos descritos são alergias levando à lesão cutânea (tipo urticária), dor no local de injeção (intramuscular), tromboflebite (injeção EV), febre e eosinofilia. As informações referentes ao uso em humanos durante a gravidez são limitadas, não sendo encontradas evidências de teratogenicidade humana com uso de polimixina $B$. $O$ quadro neurotóxico reverte com a suspensão da droga (NEIVA et al., 2013).

\section{RESISTÊNCIAÀS POLIMIXINAS}

\subsection{Mecanismos de Resistência}

O mecanismo de resistência às polimixinas carece de mais estudos, pois não se encontra completamente elucidado até o momento, porém, de uma forma geral, são observados dois fenótipos que caracterizam esse fenômeno. O primeiro, denominado resistência natural ou intrínseca, é provavelmente proveniente de uma mutação no genoma bacteriano que ocorre produzindo CIMs não tão elevados, geralmente próximos dos seus pontos de corte (GIRARDELLO; GALES, 2012).

O segundo fenótipo é denominado mecanismo adaptativo, no qual a bactéria, inicialmente sensível, torna-se resistente após a exposição em crescentes concentrações de polimixinas. Este mecanismo pode gerar isolados com CIMs muito elevadas, podendo ser maior que $128 \mu \mathrm{g} \cdot \mathrm{mL}^{-1}$. Um fenótipo oriundo desse último mecanismo pode ser revertido na ausência da pressão seletiva estabelecida pela droga (GIRARDELLO; GALES, 2012).

O principal mecanismo de resistência natural e adquirida dos Gram-negativos às polimixinas envolve modificações da membrana externa lipopolissacarídica através de alterações no lipídeo A, que é porção do LPS mais próxima dessa membrana. Isso resulta na alteração da carga negativa da superfície da célula bacteriana e na redução da afinidade com a carga positiva do antibiótico, dificultando a interação entre o fármaco e a membrana externa da célula (RIGATTO, 2011). Essas modificações do LPS são mediadas por sistemas de regulação gênica, que podem ser ativadas por fatores ambientais como concentrações elevadas de $\mathrm{Ca}^{2+}$ e baixas de $\mathrm{Mg}^{2+}$, alterações no $\mathrm{pH}$ e a presença de ferro (BARIN, 2013).

A regulação gênica do desenvolvimento de resistência às polimixinas abrange 
um sistema de dois componentes ("Two Component Systems"), utilizados por diversas espécies bacterianas para regulação da expressão de diferentes fatores de resistência e também de virulência. Eles são constituídos por uma proteína sensor de histidina quinase que sofre autofosforilação ao perceber estímulos ambientais, acarretando na ativação de uma segunda proteína citoplasmática, por uma reação de transfosforilação. A segunda proteína, então, promove a ativação ou repressão dos genes alvo, desencadeando a resistência às polimixinas (GIRARDELLO; GALES, 2012).

Várias espécies bacterianas têm desenvolvido diversos mecanismos para a modificação do lipídio A. Estudos realizados com Salmonella enterica foram os primeiros a demonstrar o envolvimento de alterações no lipopolissacarídeo (LPS) bacteriano e diminuição da atividade às polimixinas. Posteriormente, esse comportamento foi descrito também em outros isolados de Salmonella typhimurium, Yersinia pestis e Escherichia coli (GIRARDELLO; GALES, 2012). Essa alteração se dá por uma adição de 4-amino-4-desoxi-L-arabinose (LAra4N) na porção do lipídio $A$ do LPS. A biossíntese de LAra4N é mediada por PmrA/PmrB (PmrAB) e PhoP/PhoQ (PhoPQ) que são dois componentes de sistemas de regulação. Em S. typhimurium, o gene mig-14 também esta envolvido com a resistência a polimixinas (BARIN, 2013).

Essas alterações de LPS também foram descritas em outras espécies, inclusive entre microrganismos não fermentadores como $P$. aeruginosa. Mutações nos sistemas de dois componentes PhoPQ, PmrAB ou Parrs resultam na expressão constitutiva do operon do LPS modificado (arn), que codifica proteínas necessárias para a adição de LAra4N na porção do lipídio A do LPS. Esta modificação limita a interação com as polimixinas e reduz a absorção do fármaco pela bactéria (FERNÁNDEZ et al., 2013).

Essas modificações são acionadas sob baixa concentração de $\mathrm{Mg}^{2+}$ e após a exposição à concentrações subinibitórias de certos peptídeos antimicrobianos. Este processo envolve vários sistemas de dois componentes, incluindo os mencionados acima (FERNÁNDEZ et al., 2013).

O sistema $P h o P Q$ também é ativado por alterações de $\mathrm{pH}$ e alterações nas concentrações de $\mathrm{Ca}^{2+}$. Em $P$. aeruginosa este sistema também induz a transcrição de uma porina $\mathrm{OprH}$. As alterações no sistema $\mathrm{PmrAB}$ podem estar relacionadas com a resistência estável as polimixinas, devido a ativação constitutiva do sistema que resulta na modificação permanente do lipídio $A$ (BARIN, 2013).

Em A. baumannii a adição de LAra4N ainda não foi descrita. Até o momento somente alterações no operon pmrCAB foram observadas. Estes genes compõem um sistema de dois componentes: regulador de resposta ( $p m r A)$ e sensor de histidina quinase $(p m r B)$. Os genes $p m r A$ e $p m r B$ controlam a expressão do gene $p m r C$ (BARIN, 2013). A resistência esta associada com o aumento da expressão do gene 
pmrC, responsável por codificar a proteína que adiciona fosfoetanolamina no lipídio $\mathrm{A}$. Estudo em modelo animal mostrou que em $A$. baumannii com resistência a colistina por mutação do pmrB, apresenta também menor virulência, capacidade competitiva e de formação de colônias. Isso talvez explique a baixa incidência e disseminação de $A$. baumannii resistente a colistina (RIGATTO, 2011).

Entre isolados de K. pneumoniae, a resistência às polimixinas foi relacionada como aumento da produção de cápsula polissacarídica, o que diminui a interação da droga com a superfície celular (GIRARDELLO; GALES, 2012). Os sistemas envolvidos nessa mutação são o PmrAB e o PmrPQ, além das alterações no LPS. Na espécie Vibrio cholerae, a resistência à polimixina é dependente de uma porina $\mathrm{OmpU}$ da membrana externa (BARIN, 2013).

\subsection{Prevalência}

Um estudo realizado para a determinação de ribotipos de cepas produtoras de carbapenemases observou que $10 \%$ dos isolados apresentaram resistência in vitro à polimixina B (SCHENKEL, 2009). Na Índia, um estudo analisou cepas de $P$. aeruginosa e A. baumanii obtidas de pacientes hospitalizados por um período superior a 48 horas, relatando resistência em $8 \%$ dos isolados para colistina e polimixina B (SHANTHI; SEKAR, 2009). Outra pesquisa avaliou a resistência à polimixina $B$ isolados de Acinetobacter spp. provenientes de três hospitais de Porto Alegre, obtendo-se resistência em 3,3\% dos isolados (HEINECK et al., 2012).

Por fim, o programa de vigilância de resistência SENTRY durante o período 2006-2009 analisou isolados clínicos de $P$. aeruginosa e de $A$. baumanii de diversos sítios de infecção coletados em várias partes do mundo. Foi observada multirresistência em 3,3\% das amostras de $P$. aeruginosa e 3,2\% de $A$. baumanii. As taxas de resistência à polimixina $B$ foram de $2,9 \%$ na região Asia-Pacífico e de $1,1 \%$ na Europa, America Latina e America do Norte para P. aeruginosa. Em A. baumanii a resistência foi de 2,7\% na Europa, $1,7 \%$ na America do Norte e America Latina (GALES et al., 2011).

\subsection{Metodologias para Caracterização da Resistência}

Vários são os métodos empregados atualmente para a determinação da resistência in vitro das polimixinas. Entretanto, os laboratórios de análises microbiológicas do Brasil não dispõem de um guia nacional de padronização de metodologias para a realização dessas análises. Desse modo, a Agência Nacional de Vigilância Sanitária (ANVISA) preconiza a utilização das técnicas padronizadas descritas no manual do Clinical and Laboratory Standards Institute (CLSI), desenvolvido 
desenvolvido nos Estados Unidos. Algumas técnicas também são importadas da Europa através do European Committee on Antimicrobial Susceptibility Testing (EUCAST).

Um estudo comparou a eficiência de alguns testes de susceptibilidade in vitro às polimixinas, concluindo que, apesar de o método de difusão em disco ser amplamente empregado, mostrou-se pouco confiável por apresentar resultados imprecisos, como falsa-sensibilidade e valores errôneos de áreas de crescimento bacteriano. Por sua vez, os métodos baseados na CIM mostraram resultados mais eficientes e precisos. O método automatizado VITEK $2^{\circledR}$ (bioMérieux ${ }^{\circledR}$ ) utilizado para teste de suscetibilidade foi considerado uma ferramenta confiável e de fácil manipulação em isolados (LO-TEM-FOE et al., 2007).

Em resumo, para Pseudomonas spp., o manual do CLSI descreve o método da difusão em disco e as técnicas baseadas na CIM para caracterização da resistência. Já para Acinetobacter spp., apenas são descritas as metodologias de determinação da CIM. O CLSI não relata métodos para verificação de resistência em Enterobacteriaceae (CLSI, 2013). Entretanto, podem ser encontrados métodos baseados na CIM para essa família na literatura do EUCAST.

\section{CONSIDERAÇÕES FINAIS}

As polimixinas são antimicrobianos utilizados em âmbito hospitalar contra inúmeras bactérias Gram-negativas fermentadoras e não fermentadoras. Normalmente são a última escolha no tratamento de microrganismos multirresistentes.

Em meados da década de 70, vários estudos realizados com metodologias não padronizadas, classificaram as polimixinas como fármacos nefrotóxicos, resultando no abandono desses compostos químicos da terapêutica médica. Entretanto, o surgimento de bacilos Gram-negativos multirresistentes aos antimicrobianos usualmente empregados fizeram com que essa classe de medicamentos reemergisse nos últimos anos como terapia de resgate no tratamento às infecções microbianas, baseado em experiências empíricas e estudos de caso.

Embora não esteja bem eluciada, a resistência em polimixinas tornou-se uma realidade em hospitais brasileiros e a sua detecção laboratorial continua sendo um desafio, pois os métodos de investigação mais eficientes são onerosos e necessitam de mão de obra qualificada. Isso, por sua vez, resulta na inviabilização da aquisição dessas metodologias pela maioria dos laboratórios microbiológicos.

\section{REFERÊNCIAS}

BARIN, J. Avaliação da heterorresistência e resistência adaptativa à 


\section{REFERÊNCIAS}

BARIN, J. Avaliação da heterorresistência e resistência adaptativa à polimixina $B$ em isolados de Acinetobacter baumannii resistentes aos carbapenêmicos. 2013. 67f. Dissertação (Mestrado) -- Universidade Federal do Rio Grande do Sul, Faculdade de Medicina, Programa de Pós-Graduação em Ciências Médicas. Porto Alegre.

CHAMBERS, H.F. Antimicrobianos (continuação): Inibidores da síntese protéica e antibacterianos diversos. In: GOODMAN, A. G. As bases farmacológicas da terapêutica. $10^{a}$ edição. Rio de Janeiro: McGraw-Hill, 2005. p. 945-946. cap. 47.

CLSI. Performance Standards for Antimicrobial Susceptibility Testing; TwentyThird Informational Supplement. CLSI document M100-S23. Wayne: Clinical and Laboratory Standards Institute, 2013.

ELIAS, L. da S. Fatores de risco associados à mortalidade de pacientes tratados com polimixina B endovenosa. 2010. 78f. Dissertação (Mestrado em Ciências Médicas) - Faculdade de Medicina, Universidade Federal do Rio Grande do Sul. Porto Alegre.

FALAGAS, M. E.; RAFAILIDIS, P. I.; MATTHAIOU, D. K. Resistance to polymyxins: mechanisms, frequency and treatment options. Drug. Resist. Updat. Oxford, v.13, n.04, p.132-138, aug. 2010.

FERNÁNDEZ, L. et al. Characterization of the Polimyxin B Resistome of Pseudomonas aeruginosa. Antimicrob. Agents Chemother. Washington, v.57, n.01, p.110-119, jan. 2013.

GALES, A. C.; JONES, R. N.; SADER, H. S. Contemporary activity of colistin and polymyxin $B$ against a worldwide collection of Gram-negative pathogens: results from the SENTRY Antimicrobial Surveillance Program (2006-09). J. Antimicrob. Chemother. Oxford, v.66, n.09, p. 2070-2074, sep. 2011.

GIRARDELLO, R.; GALES, A. C. Resistência às polimixinas: velhos antibióticos, últimas opções terapêuticas. Rev. Epidemiol. Control. Infect. Santa Cruz do Sul, v.2, n.2, p.66-69. mai. 2012.

HEINECK, B. L. et al. Perfil de susceptibilidade aos antimicrobianos em isolados de 
cinetobacter spp. Em três hospitais de Porto Alegre: foco em resistência a carbapenêmicos e polimixina B. In: Salão de Iniciação Centífica, 24., 2012, Porto Alegre. Anais eletrônicos...Porto Alegre: Universidade Federal do Rio Grande do Sul - UFRGS, 2012. Disponível em: <http://www.lume.ufrgs.br/bitstream/handle/10183/ 63728/Poster_23625.pdf?sequence=2>. Acessado em: 15 mai 2013.

KVITKO, C. H. C. Eficácia da polimixina B no tratamento de bacteremias por Pseudomonas aeruginosa. 80f. Dissertação (Mestrado em Ciências Médicas) Faculdade de Medicina, Universidade Federal do Rio Grande do Sul. Porto Alegre.

KWA, A. L. et al. Pharmacokinetics of polymyxin B1 in patients with multidrug-resistant Gram-negative bacterial infections. Diagn. Microbiol. Infect. Dis. Oxford, v.60, p.1637. 2008.

LO-TEN-FOE, J. R. et al. Comparative evaluation of the Vitek 2, disk diffusion, Etest, broth microdilution, and agar dilution susceptibility testing methods for colistina in clinical isolates, including heteroresistant Enterobacter cloacae and Acinetobacter baumanii strains. Antimicrob. Agents Chemother. Washington, v.51, n.10, p. 372630. oct. 2007.

MENDES, C. A. C.; BURDMANN, E. A. Polimixinas: revisão com ênfase na nefrotoxicidade. Rev. Assoc. Med. Bras. São Paulo, v.55, n.6, p. 752-759, jul. 2009.

MOSTARDEIRO, M. M. Uso de polimixina em pacientes submetidos a transplante: Avaliação de eficácia e nefrotoxicidade. 2009. 53 f. Tese (Mestrado em Ciências Médicas) - Escola Paulista de Medicina, Universidade Federal de São Paulo. São Paulo.

NEIVA, L. B. de M. et al. Polimixina B: efeito dose e tempo dependente na nefrotoxicidade in vitro. Acta Paul. Enferm. São Paulo, v.26, n.1, p.57-62. fev. 2013.

OLIVEIRA, M. S. et al. Polymyxin B and colistimethate are comparable as to efficacy and renal toxicity. Diagn. Microbiol .Infect. Dis. Oxford, v. 65, n. 4, p. 431-434, dez. 2009.

RIGATTO, M. H. da S. P. Polimixina B em comparação com outros antibióticos no tratamento da pneumonia e traqueobronquite associadas à ventilação mecânica causadas por Pseudomonas aeruginosa ou Acinetobacter baumannii. $88 \mathrm{f}$. Dissertação (Mestrado em Ciências Médicas) - Faculdade de Medicina, Universidade 
Federal do Rio Grande do Sul. Porto Alegre.

SCHENKEL, T. S. Klebsiella pneumoniae carbapenemase (KPC): uma nova ameaça em resistência bacteriana. 2009. 33 f. Tese (Pós-Graduação em Análises Clínicas e Toxicológicas) - Instituto de Ciências da Saúde, Centro Universitário Feevale. Novo Hamburgo.

SHANTHI, M.; SEKAR, U. Multi-drug Resistant Pseudomonas aeruginosa and Acinetobacter baumannii Infections among Hospitalized Patients: Risk Factors and Outcomes. J Assoc Physicians. Chennai, v.57, n.636, p. 638-40, sep. 2009.

ZAVASCKI, A. P. et al. Multidrug-resistant Pseudomonas aeruginosa and Acinetobacter baumannii: resistance mechanisms and implications for therapy. Expert Rev. Anti Infect. Ther. London, v.8, n.1, p.71-93. jan.2010. 